\title{
Evidence for lodine Atoms as Intermediates in the Dye Sensitized Formation of I-I Bonds
}

\author{
James M. Gardner, Jovan M. Giaimuccio, and Gerald J. Meyer* \\ Departments of Chemistry and Materials Science and Engineering, Johns Hopkins University, 3400 North Charles \\ Street, Baltimore, Maryland 21218
}

Received September 29, 2008; E-mail: meyer@ @hu.edu

Photoinitiated reactions that form chemical bonds are of considerable importance for the conversion and storage of solar energy. ${ }^{1}$ While the $\mathrm{O}-\mathrm{O}$ bond formation necessary for solar water splitting continues to be the "holy grail" in this area, there is also considerable interest in the formation of bonds between other elements such as halogens. ${ }^{1,2}$ For example, iodide oxidation to form I-I bonds is key to sensitizer regeneration in champion dyesensitized solar cells. Mechanistic details of how iodide oxidation yields the $\mathrm{I}-\mathrm{I}$ bonds present in $\mathrm{I}_{2}{ }^{-}$and $\mathrm{I}_{3}{ }^{-}$reaction products are under active investigation ${ }^{3-5}$ but remain speculative. Here we provide the first direct evidence that electron transfer sensitized to visible light with metal-to-ligand charge transfer (MLCT) excited states can directly yield iodine atoms that subsequently react to form an I-I chemical bond.

Figure 1 shows the absorption and photoluminescence (PL) spectra of $\left[\mathrm{Ru}(\mathrm{bpz})_{2}(\mathrm{deeb})\right]\left(\mathrm{PF}_{6}\right)_{2}$, where bpz is $2,2^{\prime}$-bipyrazine and deeb is $4,4^{\prime}-\left(\mathrm{CO}_{2} \mathrm{Et}\right)_{2}-2,2^{\prime}$-bipyridine in neat acetonitrile. The measured PL quantum yield, $\phi=0.14$, and excited-state lifetime, $\tau=1.75 \pm 0.03 \mu \mathrm{s}$, were used to calculate the radiative and nonradiative rate constants, $k_{\mathrm{r}}=(8.36 \pm 0.05) \times 10^{4}$ and $k_{\mathrm{nr}}=$ $(5.01 \pm 0.02) \times 10^{5} \mathrm{~s}^{-1}$. The absorption spectrum of the one electron reduced compound $\mathrm{Ru}\left(\mathrm{bpz}^{-}\right)(\mathrm{bpz})(\mathrm{deeb})^{+}$generated by photochemical reduction is also shown in Figure 1. Ruthenium bipyrazine excited states are potent oxidants as previously reported by Lever and co-workers. ${ }^{6}$ An excited-state reduction potential of $+1.36 \mathrm{~V}$ for $\mathrm{Ru}^{\mathrm{II}^{* /+}}$ was determined ${ }^{7}$ from cyclic voltammetry (a quasi-reversible wave at $\mathrm{Ru}^{\mathrm{II} /+}=-0.82 \mathrm{~V}$ vs SCE), and an excitedstate free energy was estimated from the corrected PL spectrum, $\Delta G_{\mathrm{es}}=2.18 \mathrm{eV}$.

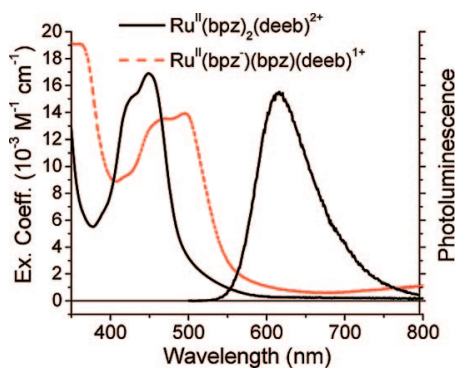

Figure 1. Room temperature absorption and photoluminescence spectra of $\mathrm{Ru}(\mathrm{bpz})_{2}(\mathrm{deeb})^{2+}$ in acetonitrile (black solid line). Also shown is the absorption spectrum of $\mathrm{Ru}\left(\mathrm{bpz}^{-}\right)(\mathrm{bpz})(\mathrm{deeb})^{+}$(dashed red line).

Pulsed $532 \mathrm{~nm}$ excitation of $\left[\mathrm{Ru}(\mathrm{bpz})_{2}(\mathrm{deeb})\right]\left(\mathrm{PF}_{6}\right)_{2}$ in neat acetonitrile induces absorption changes that are consistent with formation of the MLCT excited state, $\mathrm{Ru}\left(\mathrm{bpz}^{-}\right)(\mathrm{bpz})(\mathrm{deeb})^{2+*}$. Positive absorptions at wavelengths $<400 \mathrm{~nm}$ and $>470 \mathrm{~nm}$ were assigned to the reduced bipyrazine ligand that is evident in Figures 1 and 2. Isosbestic points were observed at 400 and $540 \mathrm{~nm}$. Excited state decay was found to be first-order with rate constants in good agreement with those abstracted from time-resolved PL data. The excited state was dynamically quenched by iodide with a Stern-Volmer constant $K_{\mathrm{sv}}=(1.1 \pm 0.1) \times 10^{5} \mathrm{M}^{-1}$ from which $k_{\mathrm{et}}=6.6 \times 10^{10} \mathrm{M}^{-1} \mathrm{~s}^{-1}$ was abstracted, Figure 2 inset. Steadystate PL measurements gave similar values.

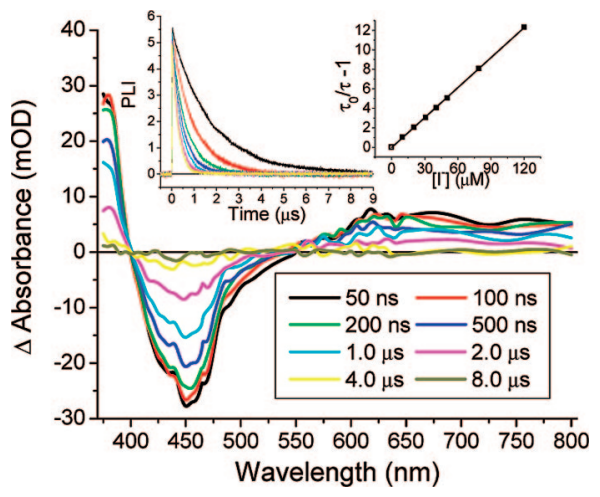

Figure 2. Transient absorption difference spectra of $\mathrm{Ru}(\mathrm{bpz})_{2}(\mathrm{deeb})^{2+}$ measured at the indicated times after pulsed $532 \mathrm{~nm}$ excitation in acetonitrile solution. The inset shows excited-state decay measured as a function of the TBAI concentration with a corresponding Stern-Volmer plot from which $\mathrm{K}_{\mathrm{SV}}=(1.1 \pm 0.1) \times 10^{5} \mathrm{M}^{-1}$ and $k_{\mathrm{et}}=6.6 \times 10^{10} \mathrm{M}^{-1} \mathrm{~s}^{-1}$.

Pulsed laser excitation under conditions identical to those in Figure 2 except for the presence of $500 \mathrm{mM}$ TBAI led to the appearance of new transient absorption features that were well described by equal concentrations of $\mathrm{Ru}\left(\mathrm{bpz}^{-}\right)(\mathrm{bpz})(\mathrm{deeb})^{+}$and $\mathrm{I}_{2}{ }^{-}$, Figure 3. The $500 \mathrm{~nm}$ absorption band is due to the reduced ruthenium compound, and the UV and weak red absorption are mainly from $\mathrm{I}_{2}^{-\bullet}$. Excited state quenching was quantitative, but the yield of charge separated products was low, $\phi_{\mathrm{ce}}<0.1$. Back electron transfer to yield ground-state products followed second-order equal concentration kinetics, $k_{\mathrm{cr}}=(2.1 \pm 0.3) \times 10^{10} \mathrm{M}^{-1} \mathrm{~s}^{-1}$.

At lower iodide concentrations $(<1 \mathrm{mM})$, the appearance of the electron transfer products was quantified with nanosecond time resolution. Shown in the inset to Figure 3 are absorption transients measured at $400 \mathrm{~nm}$ as a function of the iodide concentration. This wavelength was chosen as it is an isosbestic point between the ground and excited state (Figure 2) and is very close to a groundreduced state isosbestic point $(\lambda=404 \mathrm{~nm}$, Figure 1). The formation and decay of $\mathrm{I}_{2}^{-\cdot}$ could therefore be quantified at this wavelength without interference from other species in the solution. ${ }^{8}$ A secondorder rate constant for $\mathrm{I}_{2}{ }^{-\bullet}$ formation was abstracted from iodide concentration dependent kinetic data like that shown in Figure 3A, $k_{\mathrm{I}}=(2.4 \pm 0.2) \times 10^{10} \mathrm{M}^{-1} \mathrm{~s}^{-1}$.

The reduced ruthenium compound, $\mathrm{Ru}\left(\mathrm{bpz}^{-}\right)(\mathrm{bpz})(\mathrm{deeb})^{+}$, absorbs light most strongly at $500 \mathrm{~nm}$. Kinetic measurements at this wavelength showed that the excited state decayed with the same 


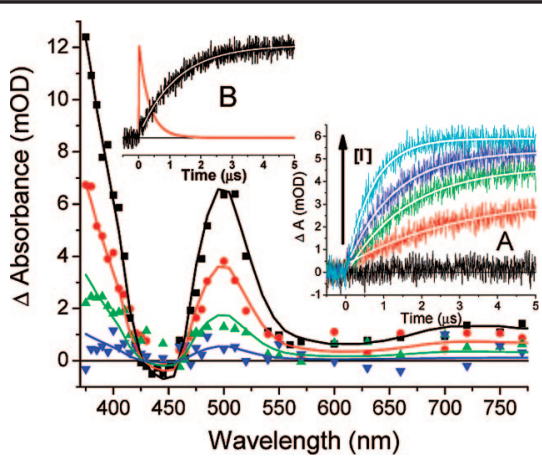

Figure 3. Transient absorption difference spectra of $\mathrm{Ru}(\mathrm{bpz})_{2}(\mathrm{deeb})^{2+}$ measured; $\boldsymbol{\square}=1.0 \mu \mathrm{s}, \boldsymbol{\bullet}=50 \mu \mathrm{s}, \boldsymbol{\Delta}=200 \mu \mathrm{s}, \boldsymbol{\nabla}=1.0 \mathrm{~ms}$ after pulsed $532 \mathrm{~nm}$ excitation in $4.4 \mathrm{mM}$ TBAI acetonitrile solution. The solid lines are simulated spectra based on the formation of a 1:1 molar ratio of $\mathrm{Ru}\left(\mathrm{bpz}^{-}\right)(\mathrm{bpz})(\mathrm{deeb})^{+}$and $\mathrm{I}_{2}^{-\cdot}$. Inset (A) shows the absorption measured at $400 \mathrm{~nm}$ as a function of increased iodide concentration. Overlaid are fits to a first-order kinetic model from which a second-order rate constant of $(2.4 \pm 0.2) \times 10^{10} \mathrm{M}^{-1} \mathrm{~s}^{-1}$ was abstracted. Inset (B) shows PL decay (red solid line) and formation of $\mathrm{I}_{2}^{-\bullet}$ (black with overlaid fit) at $30 \mu \mathrm{M}$ TBAI concentration. Analysis of the inset (B) data shows that the excited state decayed three times faster than the formation of $\mathrm{I}_{2}^{-}$.

rate constant as the appearance of the reduced compound. Secondorder rate constants abstracted from iodide concentration dependent kinetic data yielded $(6.6 \pm 0.3) \times 10^{10} \mathrm{M}^{-1} \mathrm{~s}^{-1}$ in excellent agreement with the value measured from Stern-Volmer analysis of the excited-state quenching, $(6.5 \pm 0.3) \times 10^{10} \mathrm{M}^{-1} \mathrm{~s}^{-1}$.

\section{Scheme 1}

$$
\begin{aligned}
& \mathrm{M}_{\mathrm{ox}}+\mathrm{I}^{-} \rightarrow \mathrm{M}_{\mathrm{red}}+\mathrm{I}^{\bullet} \\
& \mathrm{M}_{\mathrm{ox}}+2 \mathrm{I}^{-} \rightarrow \mathrm{M}_{\mathrm{red}}+\mathrm{I}_{2}^{-}
\end{aligned}
$$

The thermal oxidation of iodide by transition metal compounds has been proposed to occur by two distinct mechanisms, (1) and (2) in Scheme 1. ${ }^{9}$ It seems probable that excited-state reactions would follow similar pathways. Both reaction (1) and (2) are firstorder in oxidized transition metal compound $\mathrm{M}_{\mathrm{ox}}$ but are first- and second-order with respect to iodide. In principle, these pathways can be distinguished by identification of the reaction products $\mathrm{I}^{*}$ versus $\mathrm{I}_{2}^{-}$. In practice this is difficult as the iodine atom absorbs only weakly in the UV region and is known to rapidly react with iodide to generate $\mathrm{I}_{2}^{-\bullet}$. The second-order rate constant for $\mathrm{I}^{\cdot}+\mathrm{I}^{-}$ $\rightarrow \mathrm{I}_{2}{ }^{-\bullet}$ in acetonitrile was reported to be $2.3 \times 10^{10} \mathrm{M}^{-1} \mathrm{~s}^{-1.8}$. Therefore, observation of an $\mathrm{I}_{2}^{-\bullet}$ product is not sufficient proof for (2), as the first reaction can also ultimately yield $\mathrm{I}_{2}{ }^{-}$.

Here we have shown that the rate constant for excited-state decay is, within experimental error, the same as that for the appearance of the reduced compound, which firmly establishes that excitedstate electron transfer from iodide to the formally $\mathrm{Ru}(\mathrm{III})$ metal center in the excited-state produced $\mathrm{Ru}\left(\mathrm{bpz}^{-}\right)(\mathrm{bpz})(\mathrm{deeb})^{+}$with a rate constant of $k_{\mathrm{et}}=(6.6 \pm 0.3) \times 10^{10} \mathrm{M}^{-1} \mathrm{~s}^{-1}$. The appearance of $\mathrm{I}_{2}^{-\bullet}$ was three times slower indicating that it is not an excitedstate reaction product. Indeed, the measured $k_{\mathrm{I}}$ value is exactly that expected based on literature rate constants for the reaction of iodine atoms with iodide. ${ }^{8}$ Taken together this provides compelling evidence that the iodine atom is the initial product of excited-state electron transfer. The iodine atom subsequently reacts with iodide to form the $\mathrm{I}-\mathrm{I}$ bond of $\mathrm{I}_{2}^{-\bullet}$.
To our knowledge, this represents the first example of dye sensitized generation of iodine atoms. In previous work with $\mathrm{Ru}(\text { deeb)(bpy })_{2}{ }^{2+}$, an iodide ion was found to associate with each of the carbonyl ethyl ester oxygens in the solid state. The two iodides were $6.246 \AA$ apart, and although it was not proven, the spectroscopic data in $\mathrm{CH}_{2} \mathrm{Cl}_{2}$ were consistent with concerted excited-state electron transfer and $\mathrm{I}-\mathrm{I}$ bond formation. ${ }^{10}$ Related pathways have also been invoked at sensitized $\mathrm{TiO}_{2}$ interfaces where ion pairing between the oxidized sensitizer and iodide is thought to facilitate the overall termolecular reaction (2). ${ }^{3,11}$ The results here show that iodine atoms are possible intermediates and that the rapid subsequent reaction with iodide in the $0.5 \mathrm{M}$ LiI solutions typically used will significantly shorten their lifetimes.

\section{Scheme 2}

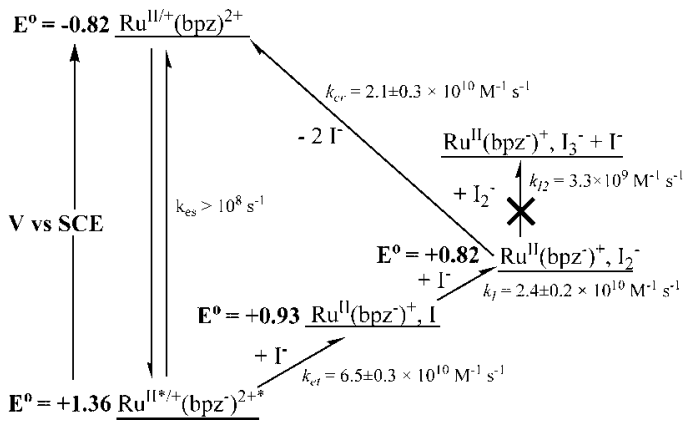

The kinetic and mechanistic information reported in this communication along with iodide reduction potentials ${ }^{12}$ is summarized in the Jablonski-type diagram shown in Scheme 2. A bpz and deeb ligand was removed for clarity. Excited state electron transfer to yield the iodine atom is $\sim 430 \mathrm{mV}$ downhill. Reaction of the iodine atom with iodide to make an I-I bond lowers the free energy stored in the charge separated state by $110 \mathrm{mV},{ }^{9,12}$ Charge recombination to yield ground-state products $\mathrm{Ru}^{+}+\mathrm{I}_{2}^{-\bullet} \rightarrow \mathrm{Ru}^{\mathrm{II}}+2 \mathrm{I}^{-}$is highly thermodynamically favored $\left(-\Delta G^{\circ}=1.64 \mathrm{eV}\right)$ and occurs with a rate constant of $2.1 \times 10^{10} \mathrm{M}^{-1} \mathrm{~s}^{-1}$, almost 10 times larger than the $\mathrm{I}_{2}^{-}$disproportionation rate constant. Unwanted charge recombination to $\mathrm{I}_{2}^{-\bullet}$ has previously been proposed to lower the efficiency of dye-sensitized solar cells, ${ }^{5}$ and these data show that it can be a very fast reaction.

Acknowledgment. This work was supported by a grant from the Division of Chemical Sciences, Office of Basic Energy Sciences, Office of Energy Research, U.S. Department of Energy (DE-FG0296ER14662).

\section{References}

(1) Bard, A. J.; Fox, M. A. Acc. Chem. Res. 1995, 28 (3), 141.

(2) Hagfeldt, A.; Gratzel, M. Acc. Chem. Res. 2000, 33 (5), 269.

(3) Clifford, J. N.; Palomares, E.; Nazeeruddin, M. K.; Gratzel, M.; Durrant, J. R. J. Phys. Chem. C 2007, 111 (17), 6561.

(4) Staniszewski, A.; Ardo, S.; Sun, Y.; Castellano, F. N.; Meyer, G. J. J. Am. Chem. Soc. 2008, 130 (35), 11586.

(5) Bauer, C.; Boschloo, G.; Mukhtar, E.; Hagfeldt, A. J. Phys. Chem. B 2002, 106 (49), 12693.

(6) Crutchley, R. J.; Lever, A. B. P. J. Am. Chem. Soc. 1980, 102 (23), 7128.

(7) Bergeron, B. V.; Meyer, G. J. J. Phys. Chem. B 2003, 107 (1), 245.

(8) Treinin, A.; Hayon, E. Int. J. Radiat. Phys. Chem. 1975, 7, 387.

(9) Nord, G. Comm. Inorg. Chem. 1992, 13 (3-4), 221.

(10) Marton, A.; Clark, C. C.; Srinivasan, R.; Freundlich, R. E.; NarducciSarjeant, A. A.; Meyer, G. J. Inorg. Chem. 2006, 45 (1), 362.

(11) Fitzmaurice, D. J.; Frei, H. Langmuir 1991, 7 (6), 1129.

(12) Wang, X.; Stanbury, D. M. Inorg. Chem. 2006, 45 (8), 3415.

\section{JA807703M}

